\title{
Ascertaining the Effects of Job Insecurity, Job Demand and Health Issues Towards Presenteeism: Case of a Malaysian Government Linked Company
}

\author{
Sharizan Sharkawi*, Mazlina Suhaimi and Murni Zarina \\ Mohamed Razali
}

University Teknologi MARA, Malaysia

\begin{abstract}
Presenteeism is an underreported phenomenon. However, people are slowly beginning to shed more light on it as workplaces become more demanding of their employees. While an employee may think he is doing well by still showing up for work despite being injured, stressed or ill, the opposite is usually true. This is due to the fact that he may end up being less productive or make many mistakes while on the job, spreading his illnesses to other workers, all of which can cost the company so much more than if he were to stay at home. This paper examined the main influencing factors that affect presenteeism in a local government linked company. The factors examined were job insecurity, job demands and health issues. Quantitative data was collected using the nonprobability self-administered questionnaire that consist of questions with 6-points Likert scales distributed to samples of 120 employees in a division within the organisation. The data collected was analysed using Pearson Correlation and Multiple Regression Analysis to determine relationship between different variables. Based on the findings, job insecurity has the strongest and most significant relationship to presenteeism, whilst job demands and health issues were weak and not significant. This study also found that job insecurity as the most influencing factor that affects presenteeism in this local government linked company. The findings have made significant contribution to the organisation towards developing initiatives focusing on job insecurity to manage future escalation of presenteeism.
\end{abstract}

Keywords: Presenteeism, Job Insecurity, Job Demand, Health Issues

\section{Introduction}

In recent years, presenteeism has emerged as an important organisational phenomenon and is normally emphasizes in the negative behaviour outcomes. According to Cooper (1996), presenteeism occurs when people are physically present in the workplace but are functionally absent. Presenteeism is the practice of workers reporting to work even when they are unhealthy or overly fatigued (Johns, 2010). As a result, they are not performing well and not operating to their usual level of productivity. Some researchers define presenteeism as to how much illness or medical condition hinders someone's performance. According to Evans (2004) and Johansson and Lundberg (2004), presenteeisn is when employees go to work despite feeling unhealthy or experiencing other events that might normally compel absence (e.g., child care problems). Whitehouse (2005) highlighted presenteeism resulted in reduced productivity at work due to health problems or other events that distract one from full productivity.

It has been estimated that presenteeism costs organisations more than sickness absence. The Healthiest Workplace Survey in 2019 by AIA Vitality shows that Malaysia has come second in terms of productivity loss after Hong Kong. The survey reported that Malaysia have lost on average 73.3 days of work time per employee per year due to absence and presenteeism. This is estimated to have cost organisations on average RM1,460,774.00 a month. Bergstrom, Bodin, Hagberg, Aronsson, and Josephson (2009) have also found that presenteeism was a significant risk factor for future sick leaves of more than 30 days, indicative of serious health problems. Continuously attending to work while sick might also cause a piling up of workload due to 
reduced efficiency, which subsequently increases the likelihood of burnout (Demerouti et al., 2009; Lu, Lin, \& Cooper, 2013) and diminishing satisfaction. Attending to work while ill may also hinder the individual's performance due to suboptimal physical/psychological conditions. Economists have attempted to estimate productivity loss with large-scale surveys of employees by quantifying presenteeism into work hours and monetary equivalent (Burton, Conti, Chen, Schultz, \& Edington, 1999). Some studies in the U.S. have estimated the cost of presenteeism to be about $\$ 150$ billion to $\$ 250$ billion annually, which represents about $60 \%$ of the total cost of worker illnesses.

There are many causes that lead to presenteeism in the workplace. According to Lohaus and Habermann (2019), workers will go to work even when they, themselves, are ill in order to save their limited sick days for when their children are sick. Some workers trudge off to work as they fear of appearing less committed to their jobs, receiving disciplinary action or even losing their jobs. Some of them may also have little or no paid sick days. Furthermore, some may come to work despite being sick because they do not want to let the team down. Some may think no one else can do their job, or that the business will suffer if they are not there.

In this case study, the Malaysian government linked company has been experiencing declining productivity from 2016 until 2018 from $96 \%$ in year 2016 to $91 \%$ in year 2018. Monitoring on medical leave for the production employees was tracked since 2016 until 2018. Based on the medical leave data, the total medical leave days have decreased from 2016 to 2018. Therefore, from the analysis of the productivity rate and medical leave data, it was quite perplexing why productivity rate for 2018 did not increase when the medical leave days had decreased. Employees' absenteeism was showing a decreasing trend whilst more employees are physically present at the workplace. Nevertheless, productivity rate was still off target. This followed to further investigations where interviews were conducted with several employees in the organisation. The phenomenon of presenteeism was happening in the organisation and the identified causes led to these three variables; job insecurity, job demands and health issues. Therefore, this study was conducted to examine the relationship between job insecurity, job demands, health issues and presenteeism; and to identify which factor would bring the most impact to presenteeism in this organisation.

\section{Literature review}

\section{Presenteeism}

Johns (2010) definition of presenteeism of "working while ill" is the one that is employed by most organisational scholars. However, the definition does not ascribe motives to presenteeism. Thus, the reasons behind it remains as empirical questions, such as one might show up ill due to love of the job, or feelings of moral obligation, or job insecurity. Regrettably, presenteeism is regarded as a negative phenomenon and should be avoided. Hemp (2004) defined presenteeism as the problem of workers being on the job but, because of illness or other medical conditions, they are not fully functioning. There are several reasons why employees go to work while they are actually sick, including job demands such as perceived pressure from colleagues not to let them down and cause them more work, a "trigger point" system providing incentives for attendance, the fear that sick leave will put promotion opportunities at risk, and the fear of dismissal (Grinyer and Singleton, 2000; McKevitt et al., 1998). Apart from such motives, there are also positive reasons why people continue to work when they could stay at home sick, for example, interesting and stimulating work and good relationships with colleagues and clients (Roelan \& Groothoff, 2010). Presenteeism also seems to be dependent on the type of health complaints employees experience, i.e. whether the complaint is serious enough to be considered as a legitimate excuse to stay at home sick.

According to Lohaus \& Habermann (2019), the other major cause of presenteeism behaviour is purported to be subjective towards job insecurity as a result of organisational downsizing, but there is also interest in identifying further causes and motives, which is focusing on the consequences of presenteeism for an individual's health. 
According to Bockerman \& Laukkanen (2010), there is not much research done in Eastern countries. Limited evidence suggests that a strong cultural imperative for hard work, long hours, working pressure, compounded with the lack of labour welfare protection at the national level and office politics in Asian societies (Bockerman \& Laukkanen, 2010) had made presenteeism worth studying. This has exacerbated the problem of presenteeism in the developing Asian societies and the more reason why it is important to be reduced in organisations.

\section{Job Insecurity}

Job insecurity refers to employee's negative reactions to the changes concerning their jobs as well as the fear that they may lose their jobs (De Witte, 1999, 2000). A more formal definition of job insecurity describes it as the worry experienced by an individual in relation to the continuation of the present job (De Witte, 1999; Hartley, et al., 1991; Heaney, Israel, \& House, 1994; Rosenblatt \& Ruvio, 1996; Sverke \& Hellgren, 2002). Job insecurity is perceived as the feeling of powerlessness to maintain desired continuity in a threatened job situation which could be due to downsizing, organisational restructuring and economic instability.

Studies globally have highlighted job insecurity as an overall concern about future job existence (Van Vuuren, 1990, Hartley, Jacobson, Klandermans, \& Van Vuuren, 1991). While according to Hui and Lee (2000), job insecurity means a lack of control to maintain desired continuity in a threatened job situation. A survey conducted by Chartered Institute of Personnel \& Development (CIPD, 2018) has reported that people are worried about not being paid and that they do not want to fall behind with their work. The report also highlighted that with the current economy uncertainty, employees are scared to take sick leaves because their performance will be affected and eventually their job will be at stake. Therefore, job insecurity can be implied as the feeling of pressure to attend to work even when unwell. Thus, it is hypothesized that,

Hypothesis 1 (H1): There is relationship between job insecurity and presenteeism.

\section{Job Demands}

Job demands refer to those physical, social or organisational aspects of the job that require sustained physical and/or psychological (i.e. cognitive or emotional) effort on the part of the employee and are therefore associated with certain physiological and/or psychological costs (e.g., exhaustion) (Demerouti et al., 2001). Demand of psychology includes work mental demand for example working fast, needing intense concentration and /or being interrupted. Demands of physically such as higher workload, understaffing, overtime and time pressure, along with difficulty of finding cover were found to be key reasons why people might not take a day off (LeBlanc, 2009).

Latest study done by Wang, Chen, Lu, Einsenberger and Fosh (2018) stated there are positive links between workload and presenteeism. Employees who experience higher workload tend to have higher presenteeism than others. Brun, Ivers, Biron, and Cooper (2006), found that job demand is related to presenteeism via burnout. They suggest that presenteeism may arise from the strain and burnout that is related with overcoming excessive job demands as well as the reduced work engagement and higher burnout provoked by a lack of resources in the workplace.

Since job demands have to be met in order to perform adequately, employees will be inclined to do everything they can to meet these demands so that their performance remains at the desired level. Therefore, we expect that the higher the job demands, the higher the effort employees will invest in meeting them and the higher the probability that they will work while sick in order to avoid performance decrements. From this point of view, job demands not only imply feeling pressure to work harder, but also feeling pressure to attend even when experiencing job burnout. Thus, it is hypothesized that, 
Hypothesis 2 (H2): There is relationship between job demands and presenteeism.

\section{Health Issues}

Study conducted by Aronsson and Lundberg (2004) found that at least one-third of a subsample of 3,801 Swedish employees had gone to work despite being ill two or more times during the last year. They further concluded that in a state of poor health, the employees have two alternatives which is sickness absence or sickness presence. Employees who repeatedly go to work despite being ill may not get the necessary rest and accompanying recuperation and this may lead to accumulated stress and negative mental load (McEwen, 1998).

Previous researches conducted have reported a positive correlation between health issues and presenteeism. Aronsson and Gustafsson (2005) showed that health issues were the strongest determination of presenteeism. Symptoms related to presenteeism involve pain and distress for example; musculoskeletal pain, disturbed sleep, fatigue and minor depression. Johns (2010) explained that fully productive regular attendance is interrupted by "health issues" that is either acute (e.g., the flu), episodic (e.g., migraine), or chronic (e.g., the onset of diabetes). The nature of the health issues are the severity of the sickness which will dictate whether absenteeism or presenteeism ensues. Past researches have also mentioned that the theory of presenteeism must recognize the essential subjectivity of people's evaluation of their own health status (Fleten, Johnsen, \& Førde, 2004; Kaplan \& Baron-Epel, 2003) and accommodate well-established individual differences in the propensity for selfdisclosure of chronic illness at work (Munir, Leka, \& Griffeths, 2005), perceptions of how work affects health (Ettner \& Grzywacz, 2001), and the tendency to adopt a sick role (Levine \& Kozloff, 1978). Thus, it is hypothesized that,

Hypothesis 3 (H3): There is relationship between health issues and presenteeism.

\section{Methodology}

\section{Research Design}

A research design embodies the design and plans employed in gathering, analyzing and interpreting data. It includes the basic structure of the study. This is a case study using a quantitative approach focusing on the phenomena experienced by this Malaysian government linked organisation. It incorporates a scientific research inquiry designed to study the relationship between $\mathrm{n}$ the independent and dependent variables. The research instruments comprised of self-administered questionnaires (primary source). A set of questionnaires using Likert type scale (1-6) were administered to respondents. It was found that the cronbach's alpha value for this study is reliable where the overall reliability test is 0.711 . Data collected were analysed using SPSS software (version 24.0).

\section{Measurement}

The items used to measure all variables included in this study have been adapted from previous researchers. The questionnaires consist of two components: (i) to describe the demographic profiles; (ii) comprised of Likert type scale's (1-6) questions. To measure presenteeism, Stanford Presenteeism Scale (SPS-6) by Koopman et. al. (2002) was used; for job insecurity factor, Job Insecurity Questionnaire (JIQ) by De Witte (2000) was used; for job demand factor, The Job Content Questionnaire (JCQ) by Karasek et.al. (1998) was adopted and for health issues factor Short-Form Health Survey (SFHS) by Ware and Sherbourne (1992) was used. Each factor represents questions consist of 6-item, 11-item, 11-item and 10-item respectively. 


\section{Sampling}

The sample of target population was drawn from employees working in this Malaysian government linked company under the research innovation and production unit. The number of sample size for the given population was 200 (i.e. the total headcount in the unit), and by referring to Krejcie and Morgan (1970), this study selects 120 respondents.

\section{Data Analysis}

Data analysis of the study has been analysed using SPSS version 24. In order to identify the relationships between variables, pearson correlation analysis was performed and to test the hypotheses. Then multiple regression analysis was carried out to identify the most significant predictor that influenced presenteeism in the organisation.

\section{Results}

In this section, the relationship between independent variables and dependent variable were analysed. There are three (3) hypotheses that have been hypothesized in this study, H1, H2, and H3 and the results will be revealed below.

Table 1: Correlation Results Between Job Insecurity, Job Demand, Health Issues and Presenteeism

\begin{tabular}{llc}
\hline & & Presenteeism \\
\hline Job Insecurity & Pearson Correlation & $.703^{* *}$ \\
& Sig. (2-tailed) & .000 \\
Job Demand & $\mathrm{N}$ & 120 \\
& Pearson Correlation & .089 \\
& Sig. (2-tailed) & .000 \\
Health Issues & $\mathrm{N}$ & 120 \\
& Pearson Correlation & .078 \\
& Sig. (2-tailed) & .000 \\
& $\mathrm{~N}$ & 120 \\
\hline
\end{tabular}

**. Correlation is significant at the 0.01 level (2-tailed)

As presented in Table 1, the results show job insecurity $\mathrm{r}=0.703 * *(\mathrm{p}<0.05)$; job demand $\mathrm{r}=0.089(\mathrm{p}<0.05)$; health issues $\mathrm{r}=0.078(\mathrm{p}<0.05)$ which concludes that only job insecurity has a high positive relationship with presenteeism, whilst job demand and health issues have no relationship. This means only one hypothesis, $\mathrm{H} 1$ is accepted, whilst $\mathrm{H} 2$, and $\mathrm{H} 3$ are not accepted (Refer to Table 2 for the summary of hypothesis testing). The findings for $\mathrm{H} 1$ are consistent with previous studies by Mathebula et al. (2015) and Lohaus \& Habermann (2019). However, results for H2, and H3 contradict with past studies. More details will be discussed in the next section on why this could be the case for this organisation. 
Table 2: Summary of Hypothesis Testing

Hypothesis

\begin{tabular}{lll}
\hline H1 & There is relationship between job insecurity and presenteeism & Accepted \\
H2 & There is relationship between job demand and presenteeism & Not Accepted \\
H3 & There is relationship between health issues and presenteeism & Not Accepted
\end{tabular}

Next, Table 3 shows that job insecurity to be the highest variable that influence presenteeism because $(\beta=0.712$, $\mathrm{p}=0.000, \mathrm{p}<0.01$ ); which means that $71.2 \%$ of job insecurity influence presenteeism. This is followed by job demand $(\beta=0.095, p=0.162, p>0.01)$ and health issues $(\beta=0.138, p=0.044, p>0.01)$; which means that both factors do not have significant relationship with presenteeism. Therefore, job insecurity is the only factor that has relationship with presenteeism and affects presenteeism the most.

Table 3: Multiple Regression Results Between Job Insecurity, Job Demand, Health Issues and Presenteeism

\begin{tabular}{llc}
\hline JModel & $\begin{array}{l}\text { Standardized } \\
\text { Coefficients } \\
\text { (Beta) }\end{array}$ & (p) \\
\hline Job Insecurity & .712 & .000 \\
Job Demand & .095 & .162 \\
Health Issues & .138 & .044 \\
Adjusted R2 & & .506
\end{tabular}

As illustrated in Table 3, model summary above indicated that the R-square shows about 50.6\% variations in dependent variable (presenteeism) are explained by all the three independent variables namely, job insecurity, job demand and health issues. Hence, the other $49.4 \%$ variations are explained by the other independent variables that are not studied in this research.

\section{Conclusion}

Findings from the study showed that there is a significant positive relationship between job insecurity and presenteeism. However, there seemed to be no relationship between job demand and health issues towards presenteeism. The results further showed that job insecurity has the most influencing factor towards presenteeism and again both job demand and health issues did not reflect any relationship with presenteeism as derived from the multiple regression test. The result for job insecurity is well supported by previous studies. According to Mathebula et al., (2015) and Lohaus \& Habermann (2019), where major causes of job insecurity in the workplace are employment downsizing, financial crisis, lack of experience and training, technology changes, racism, gender bias and lack of education. From the researcher's investigation, the Malaysian government linked company is facing turbulent financial problems and there were rumours that the company might downsize. There were perceptions that their employment might be at risk which leads to the lack of control to maintain desired continuity in a threatened job situation. Thus, this explains why employees in this organisation are feeling insecure and continue to come to work and feel scared to take medical leave which will then affect their performance. There is the perception that they must ensure of their attendance and visibility even though they might not be effective enough to work.

However, results for job demand and health issues seemed to contradict with past studies. This is quite unique to this organisation as many previous studies showed significant relationship between these two variables with 
presenteeism such as by Wang et.al. (2018); Brun et.al. (2006); Aronsson and Gustafsson (2005); and Johns (2010). Further investigation on the organisation justified the findings; whereby employees in this organisation is well backed up by other employees. Some critical process that required special skills had at least three trained staffs to ensure there are sufficient back-up and minimal disruption in operations if one of them is sick or unavailable. With respect to health issues, employees in this organisation are well aware of their health conditions as the company had implemented an initiative of "monthly screening test". A downward trend of medical leave was recorded over the recent years and this proved that the programme had helped to alleviate unplanned absenteeism due to sickness.

Therefore, interesting findings were unearthed and unique to this study whereby job insecurity seemed to be the only variable that has any influence towards presenteeism. The organisation should take this as a clear indication that more efforts need to be addressed in this area so as to reduce presenteeism and eventually increase productivity. Maybe it would be a tall order for the company to turnaround to a better financial healthy situation in the short term but management could at least engage in a more transparent communication rather than just leaving it to the "grapevine". More open communication, teambuilding activities and town-hall meetings should be held with the employees to minimise any concerns of uncertainties and feelings of insecurity about their jobs. Management must be able to manage this situation well and put themselves in the place of the employees as it can be very sensitive. The company could also consider hiring people on contract basis in the future and investing more on technology to minimise human dependency.

For future research, researchers could extend the study to include other variables that may be unique to the companies being studied, or conduct a more representative study that includes wider sectors and industries. Next, other factors of presenteeism could also be analysed to fully understand the relationship between variables such as, employees' personality, work attitudes, social dynamics, social expectations and many others. This could enhance the presenteeism field of study as it is considered to be still at an early stage.

\section{Acknowledgement}

The authors would like to extend their thanks to the Research Management Institute of Universiti Teknologi MARA for partially funding this study under the faculty grant.

\section{References}

Aronsson G, Gustafsson K. (2005), Sickness presenteeism: prevalence, attendance-pressure factors, and an outline of a model for research, J Occup Environ Med. 2005;47(9):958-966.

Bergström, G., Bodin, L., Hagberg, J., Aronsson, G. and Josephson, M. (2009), Sickness presenteeism today, sickness absenteeism tomorrow? A prospective study on sickness presenteeism and future sickness absenteeism, Journal of Occupational and Environmental Medicine, Vol. 51 No. 6, pp. 629-638.

Bockerman, P. and Laukkanen, E. (2010), What makes you work while you are sick? Evidence from a survey of workers, The European Journal of Public Health, Vol. 20 No. 1, pp. 43-46. doi: 10.1093/eurpub/ckp076.

Brun, J. P., Ivers, H., Biron, C., \& Cooper, C. (2006). At work but ill: psychosocial work environment and wellbeing determinants of presenteeism propensity. Journal of Public Mental Health, 5(4), 26-37. doi:10.1108/17465729200600029

Burton, W.N., Chen, C.Y., Conti, D.J., Schultz, A.B. and Edington, D.W. (2006), The Association between health risk change and presenteeism change, Journal of Occupational and Environmental Medicine, Vol. 48 No. 3, pp. 252-263.

Cooper, C. (1996), "Hot under the collar", Times Higher Education Supplement, June 21, pp. 12-16.

Cooper, C., \& Lu, L. (2016). Presenteeism as a global phenomenon: Unraveling the psychosocial mechanisms from the perspective of social cognitive theory. Cross Cultural \& Strategic Management, 23(2), 216-231. doi:10.1108/CCSM-09-2015-0106 
Demerouti, E., Le Blanc, P. M., Bakker, A. B., Schaufeli, W. B., \& Hox, J. (2009). Present but sick: a threewave study on job demands, presenteeism and burnout. Career Development International.

Demerouti, E., Bakker, A. B., Nachreiner, F., \& Schaufeli, W. B. (2001). The job demandsresources model of burnout. Journal of Applied Psychology, 86, 499 -512. http://dx.doi.org/10.1037/0021-9010.86.3.499

De Witte, H. (1999). Job Insecurity and Psychological Well-being: Review of the Literature and Exploration of Some Unresolved Issues. European Journal of Work and Organizational Psychology, 8(2), 155-177.

De Witte, H. (2000). Work ethic and job insecurity: measurement and consequences for well-being, satisfaction and commitment at work.

Ettner, S.L. and Grzywacz, J.G. (2001) Workers' Perceptions of How Jobs Affect Health: A Social Ecological Perspective. Journal of Occupational Health Psychology, 6, 101-113. http://dx.doi.org/10.1037/10768998.6.2.101

Evans, C. J. (2004). Health and work productivity assessment: State of the art or state of flux? Journal of Occupational and Environmental Medicine, 46, S3-S11.

Fleten, N., Johnsen, R. \& Førde, O.H. Length of sick leave - Why not ask the sick-listed? Sick-listed individuals predict their length of sick leave more accurately than professionals. BMC Public Health 4, 46 (2004). https://doi.org/10.1186/1471-2458-4-46

Grinyer, A. and Singleton, V. (2000), "Sickness absence as risk-taking behaviour: a study of organizational and cultural factors in the public sector", Health, Risk \& Society, Vol. 2, pp. 7-21.

Hartley, J., Jacobson, D., Klandermans, B., \& van Vuuren, T. (1991). Job insecurity: Coping with jobs at risk. London: Sage.

Heaney, C.A., Israel, B. A., \& House, J. S. (1994). Chronic job insecurity among automobile workers: Effects on job satisfaction and health. Social Science \& Medicine, 38, 1431-1437.

Hemp, P. (2004). Presenteeism: at work--but out of it. Harvard Business Review, 82(10), 49-58, 155.

Hui, C., \& Lee, C. (2000). Moderating effects of organization-based self-esteem on organizational uncertaintyemployee response relationships. Journal of Management, 26, 215232.http://dx.doi.org/10.1177/014920630002600203

Johns, G. (2009). Presenteeism in the workplace: A review and research agenda. Journal of Organizational Behavior, 31(4), 519-542.

Kaplan, G. and Baron-Epel, O. (2003) What lies behind the subjective evaluation of health status? Social $\begin{array}{llll}\text { Science } \quad \& \quad \text { Medicine, } & \text { 1669-1676. }\end{array}$ http://dx.doi.org/10.1001/jama.298.14.1685

Karasek, Robert \& Brisson, Chantal \& Kawakami, Norito \& Houtman, Irene \& Bongers, Paulien \& Amick, Ben. (1998). The Job Content Questionnaire (JCQ): An Instrument for Internationally Comparative Assessments of Psychosocial Job Characteristics. Journal of occupational health psychology. 3. 322-55. 10.1037/10768998.3.4.322.

Koopman, C., Pelletier, K. R., Murray, J. F., Sharda, C. E., Berger, M. L., Turpin, R. S.,Bendel, T. (2002). Stanford presenteeism scale: health status and employee productivity. Journal of Occupational and Environmental Medicine / American College of Occupational and Environmental Medicine, 44(1), 14-20.

Krejcie, R. V., \& Morgan, D. W. (1970). Determining Sample Size for Research Activities. Educational and Psychological Measurement, 30(3), 607-610.

LeBlanc, V.R. (2009). The effects of acute stress on performance: implications for health professions education. Acad Med. 2009;84 (10 Suppl): doi:10.1097/ACM.0b013e3181b37b8f

Lohaus, D., \& Habermann, W. (2019). Presenteeism: A review and research directions. Human Resource Management Review, 29(1), 43-58.

Mathebula, L., Mukuka, M., Aigbavboa, C., \& Thwala, W. D. (2015). A theoretical assessment of causes of job insecurity in the construction industry.

McEwen BS (1998) Protective and damaging eVects of stress mediators. N Engl J Med 338(3):171-179 
McKevitt, C., Morgan, M., Dundas, R., \& Holland, W. W. (1997). Sickness absence and "working through" illness: A comparison of two professional groups. Journal of Public Health Medicine, 19(3), 295-300.

Munir F, Leka S, Griffiths A. Dealing with self-management of chronic illness at work: predictors for selfdisclosure. Soc Sci Med. 2005;60(6):1397-1407. doi:10.1016/j.socscimed.2004.07.012

Roelen, C. A. M., \& Groothoff, J. W. (2010). Rigorous management of sickness absence provokes sickness presenteeism.

Rosenblatt, Z., \& Ruvio, A. (1996). A test of multidimensional model of job insecurity and its effects on work attitudes. European Journal of Work and Organizational Psychology, 8, 197-217

Sverke, M., \& Hellgren, J. (2002). The nature of job insecurity: understanding employment uncertainty on the brink of a new millennium. Applied Psychology: An International Review, 51, 23-42.

Van Vuuren, C. V., \& Klandermans. P. G. (1990). Individual reactions to job insecurity: An integrated model. In P. J. D. Drenth \& J. A. Sergeant (Eds.), European perspectives in psychology (pp. 133-146). Chichester, England: Wiley.

Wang, Y., Chen, C.-C., Lu, L., Eisenberger, R., \& Fosh, P. (2018). Effects of leader-member exchange and workload on presenteeism. Journal of Managerial Psychology, 33(7/8), 511-523. doi:10.1108/JMP-11-20170414

Ware, J., \& Sherbourne, C. (1992). The MOS 36-Item Short-Form Health Survey (SF-36): I. Conceptual Framework and Item Selection. Medical Care, 30(6), 473-483. Retrieved from http://www.jstor.org/stable/3765916

Whitehouse, David. "Workplace presenteeism: how behavioral professionals can make a difference." Behavioral Healthcare Tomorrow, vol. 14, no. 1, 2005, p. 32+. Gale Academic 